\title{
Methylation of SLFN11 is a marker of poor prognosis and cisplatin resistance in colorectal cancer
}

\begin{abstract}
Aim: The expression of human SLFN11 was reported to sensitize cancer cells to DNA damaging agents. This study is to explore the epigenetic change and the function of SLFN11 in human colorectal cancer (CRC). Materials \& methods: Six CRC cell lines and 128 primary CRC samples were used. Results: SLFN11 was methylated in 55.47\% (71/128) of primary CRC. The expression of SLFN11 was regulated by promoter region methylation. Methylation of SLFN11 was significantly associated with age, poor 5-year overall survival and 5-year relapse-free survival (all $p<0.05$ ). SLFN11 suppressed CRC cell growth both in vitro and in vivo and sensitized CRC cells to cisplatin. Conclusion: SLFN11 is frequently methylated in human CRC, and the expression of SLFN11 is regulated by promoter region methylation. Methylation of SLFN11 reduced the sensitivity of CRC cells to cisplatin.
\end{abstract}

First draft submitted: 1 February 2017; Accepted for publication: 27 March 2017; Published online: 13 April 2017

Keywords: cisplatin $\bullet$ colorectal cancer $\bullet$ DNA damage repair $\bullet$ epigenetics $\bullet$ methylation - SLFN11

Colorectal cancer (CRC) is the third most common cancer and the fourth most common cause of cancer-related death worldwide [1]. Incidence is low at ages younger than 50 years but increases significantly with age. Median age at diagnosis is approximately 70 years in developed countries. However, rapid increases of CRC incidence have been noted with the changes in $\mathrm{di}$ etary patterns in China [2]. Most sporadic cases have chromosomal instability, an allelic imbalance at several chromosomal loci, chromosomal amplification and translocation [3]. Defects in DNA damage repair and checkpoint control can result in gene mutations and chromosomal instability to promote tumorigenesis [4,5]. Familial adenomatous polyposis and Lynch syndrome, which are caused by gene mutations in the DNA mismatch repair system, account for less than $5 \%$ of all CRC [6]. Aberrant methylation changes in DNA damage repair genes were reported to be an important mechanism of

\section{CRC development [7].}

The Schlafen (SLFN) gene family was first identified by Schwarz and co-workers in 1998 [8]. To date, five human SLFN genes have been identified [9,10]. SLFN gene products have been demonstrated to be involved in cell biological processes including proliferation, differentiation and immune function [11]. From the Cancer Genome Atlas database, SLFN11 has a wide expression range [12]. The expression of human SLFN11 was reported to sensitize cancer cells to DNA-damaging agents [13,14]. High SLFN11 expression independently predicts overall survival (OS) in a group of ovarian cancer patients treated with cisplatin-containing regiments [13]. The role and epigenetic regulation of SLFN11 in human CRC remain to be elucidated.

\section{Materials \& methods}

Human tissue samples \& cell lines

Six CRC cell lines (RKO, DLD1, SW620, LOVO, Ls180 and DKO) were examined
Tao $\mathrm{He}^{1,2}$, Meiying Zhang ${ }^{1,3}$, Ruipan Zheng ${ }^{1,3}$, Shufang Zheng', Enqiang Linghu', James G Herman ${ }^{3}$ \& Mingzhou Guo*,1

'Department of Gastroenterology \& Hepatology, Chinese PLA General Hospital, \#28 Fuxing Road, Beijing 100853, China 2Department of Pathology, The Affiliated Hospital of Logistics University of Chinese People's Armed Police Force, Tianjin 300162, China

${ }^{3}$ Medical College, NanKai University, Tianjin 300071, China

${ }^{4}$ The Hillman Cancer Center, University of Pittsburgh Cancer Institute, Pittsburgh, PA 15213, USA

*Author for correspondence: Tel.: +8610669 3765 Fax: +861068180325 mzguo@hotmail.com 
Table 1. Primer sequences and PCR conditions.

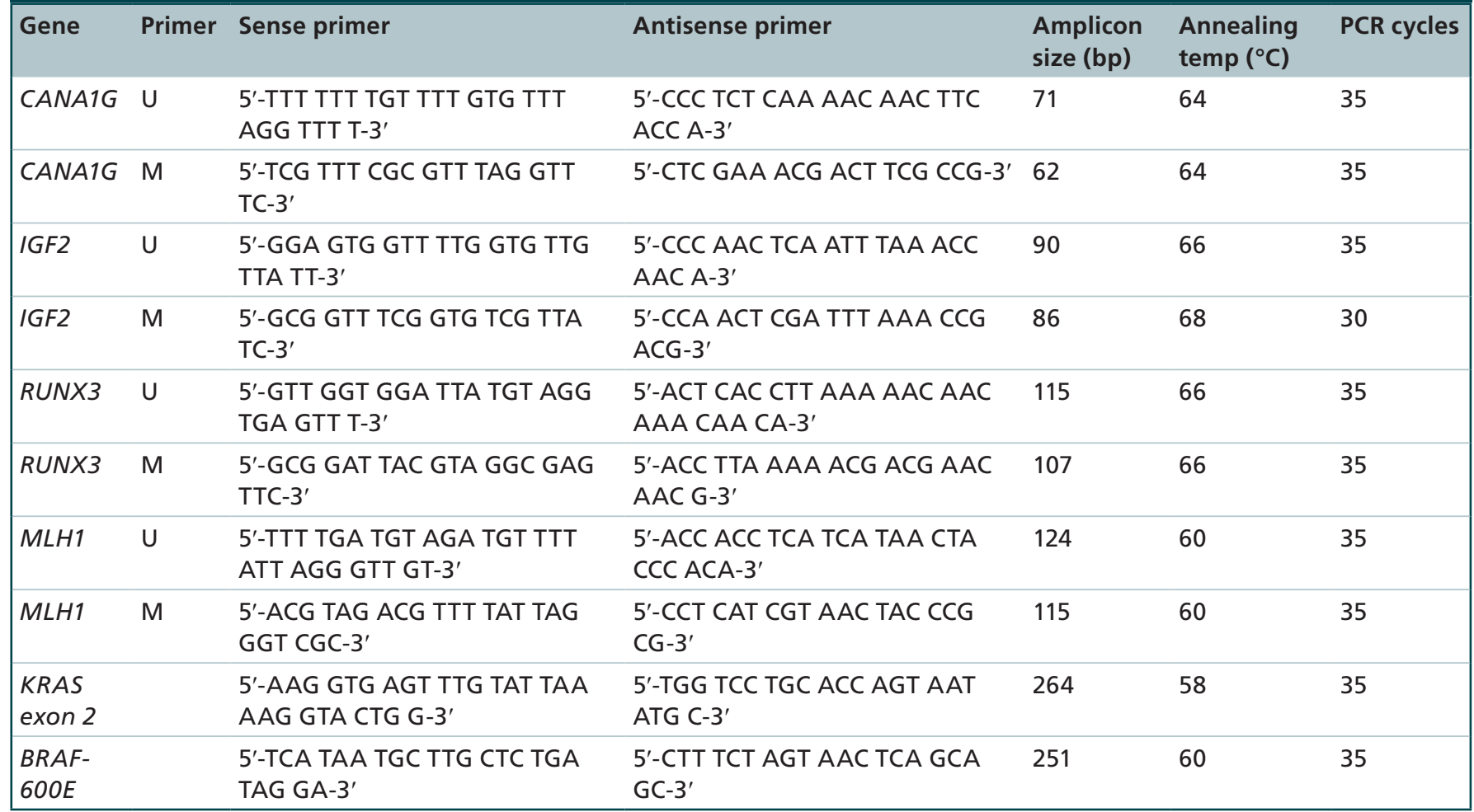

in this study and maintained in 90\% Roswell Park Memorial Institute (RPMI) 1640 media supplemented with $10 \%$ fetal bovine serum, $100 \mathrm{U} / \mathrm{ml}$ penicillin and $100 \mathrm{mg} / \mathrm{ml}$ streptomycin. 293T cells were cultured in Dulbecco's modified Eagle's medium supplemented with $10 \%$ fetal bovine serum. All cell lines were cultured in an atmosphere of $5 \%$ carbon dioxide at $37^{\circ} \mathrm{C}$.

A total of 128 cases of primary CRC and five cases of noncancerous colorectal mucosa were collected from the Chinese PLA General Hospital in Beijing between May 2009 and November 2013. All cancer samples were classified according to WHO Classification of Digestive Tumors: the Fourth Edition [15]. This study was approved by the Chinese PLA General Hospital's institutional review board.

\section{5-aza-2'-deoxycytidine treatment}

CRC cell lines (RKO, DLD1, SW620, LOVO and Ls180) were split to a low density ( $30 \%$ confluence) $12 \mathrm{~h}$ before treatment with $2 \mu \mathrm{M} 5$-aza-2'-deoxycytidine (5-AZA, Sigma, MO, USA). Growth medium conditioned with 5-AZA at $2 \mu \mathrm{M}$ was exchanged every $24 \mathrm{~h}$ for a total of $96 \mathrm{~h}$. At the end of the treatment course, RNA was extracted from the cells as described below.

RNA isolation \& semiquantitative reverse transcription PCR

Total RNA was extracted using Trizol reagent; cDNA was synthesized according to the manufacturer's instructions (Invitrogen, CA, USA) and glyceraldehyde-3-phosphatedehydrogenase $(G A P D H)$ was used as control. The SLFN11 PCR primer sequences were as follows: 5'-AACGCCCGATAACCTTCACA-3' (forward) and 5'-CTAAGGGGAGGCCCACTAGA-3' (reverse). Thermal cycling parameters were as follows: $95^{\circ} \mathrm{C} 5 \mathrm{~min} ;\left(95^{\circ} \mathrm{C} 30 \mathrm{~s}, 60^{\circ} \mathrm{C} 30 \mathrm{~s}\right.$ and $\left.72^{\circ} \mathrm{C} 30 \mathrm{~s}\right)$ 35 cycles; $72^{\circ} \mathrm{C} 5 \mathrm{~min}$. The GAPDH PCR primer sequences were as follows: 5'-GACCACAGTCCATGCCATCAC-3' (forward) and 5'-GTCCACCACCCTGTTGCTGTA-3' (reverse). Thermal cycling parameters were as follows: $95^{\circ} \mathrm{C} 5 \mathrm{~min} ;\left(95^{\circ} \mathrm{C}\right.$ $30 \mathrm{~s}, 63^{\circ} \mathrm{C} 30 \mathrm{~s}$ and $\left.72^{\circ} \mathrm{C} 40 \mathrm{~s}\right) 25$ cycles; $72^{\circ} \mathrm{C} 5 \mathrm{~min}$.

KRAS \& BRAF mutation detection, bisulfite modification, methylation-specific PCR

\& bisulfite sequencing

Genomic DNA from colorectal cell lines and CRC tissue samples were prepared by the proteinase- $\mathrm{K}$ method. KRAS codons 12 and 13 and BRAF codon 600 were amplified by PCR and sequenced according to previously reports $[16,17]$. The primer sequences are listed in Table 1. SLFN11 methylation-specfic PCR (MSP) and bisulfite sequencing (BSSQ) were performed as described previously [18]. DNA samples were then purified with the Wizard DNA Clean-Up System (Promega, CA, USA). MSP primers were designed as follows: 5'-ATTATTAG- 
TAGCGTGACGGTTATC-3' (M-forward), 5'-CGACAAATATACAAATTAAACCGCG-3' (M-reverse), 5'-TATATTATTAGTAGTGTGATGGTTATT-3' (U-forward) and 5'-ATACAACAAATATACAAATTAAACCACA-3' (U-reverse). Thermal cycling parameters were as follows: $95^{\circ} \mathrm{C} 5 \mathrm{~min} ;\left(95^{\circ} \mathrm{C} 30 \mathrm{~s}, 58^{\circ} \mathrm{C} 30 \mathrm{~s}\right.$ and $72^{\circ} \mathrm{C} 40$ s) 35 cycles; $72^{\circ} \mathrm{C} 5$ min. BSSQ primers were designed including the MSP region in a 225-bp region upstream of the SLFN11 transcription start site (-319 to $-544 \mathrm{bp})$. BSSQ primers were designed as follows: 5'-TAGAAAAGTAGAAYGTTGGTAG-3' (forward) and 5'-CAAAAAATAAATCTTAAAAAC-3' (reverse). Thermal cycling parameters were as follows: $95^{\circ} 5 \mathrm{~min}$; $\left(95^{\circ} 30 \mathrm{~s}, 55^{\circ} 30 \mathrm{~s}\right.$ and $\left.72^{\circ} 40 \mathrm{~s}\right) 35$ cycles; $72^{\circ} 5 \mathrm{~min}$. Methylation status was detected by MSP in four genes (RUNX3, CACNA1G, IGF2 and MLH1) to represent $\mathrm{CpG}$ island methylator phenotype (CIMP) as described previously [19]. The primer sequences are listed in Table 1.

\section{Construction of human full length SLFN11} cDNA lentiviral expression vector \& transient full length SLFN11 cDNA pcDNA3.1(+) expression vectors

The human full length SLFN11
(NM_001104587) was cloned into the PCDH (pCDHCMV-MCS-EF1-Puro) lentiviral plasmid (Genetimes ExCell Technology, Shanghai, China). Transfection was performed at a ratio of 1:3 (DNA mass:lipo mass) following the manufacturer's instructions for Lipofectamine 3000 Reagent (Invitrogen, CA, USA). Packaged recombinant lentiviruses were harvested from the supernatant of cell cultures at $48 \mathrm{~h}$ post-transfection. RKO and DLD1 cells were then infected with viral supernatant. Cells stably expressing SLFN11 were selected with puromycin at a concentration of $2 \mu \mathrm{g} / \mathrm{ml}$ for 2 weeks.

For transient transfection, the human full length SLFN11 cDNA (NM_001104587) was cloned into the pcDNA3.1(+) plasmid (Era Biotech, Shanghai, China). Transfection was performed according to the manufacturer's instructions by using Lipofectamine 2000 in SW620 cell (Invitrogen, CA, USA).

\section{siRNA knockdown technique}

Selected siRNAs targeting SLFN11 and RNAi negative control duplex (Gene Pharma, Shanghai, China) were used in this study. The sequences were as follows: siRNA-1726 duplex (sense: 5'-CCAGGAUAU-

\section{(A)}

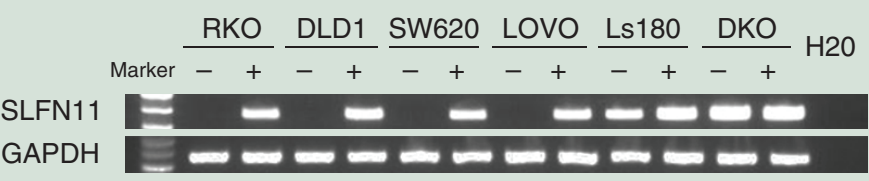

(B)

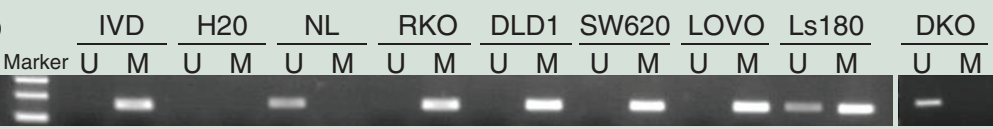

(C)

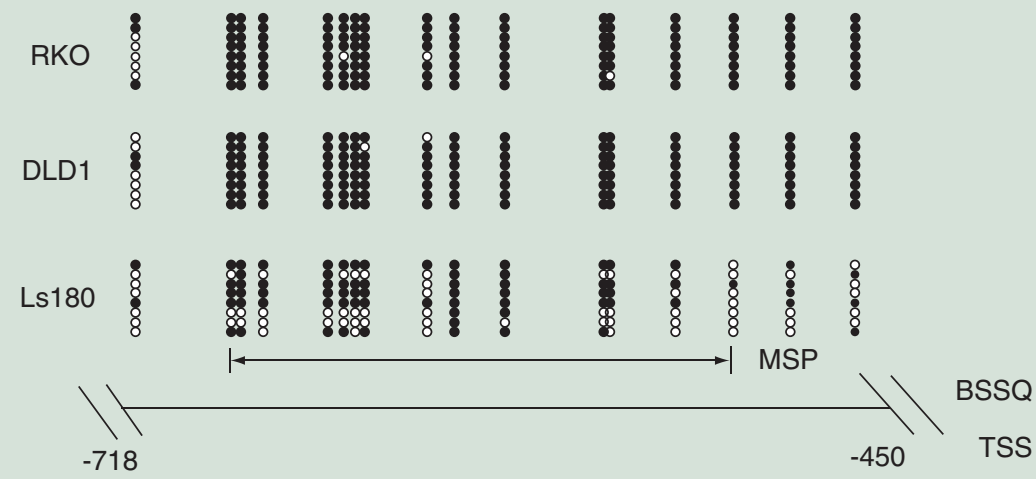

Figure 1. Expression of SLFN11 is silenced by DNA methylation in colorectal cancer cell lines. (A) RT-PCR shows the levels of SLFN11 expression - (-) untreated; (+) 5-AZA treated; $\mathrm{H}_{2} \mathrm{O}$ : double distilled water. GAPDH was used as internal control. (B) MSP results of SLFN11 in colorectal cancer cell lines. (C) Bisulfite sequencing results: the double-headed arrow indicates the region of the MSP product.

5-AZA: 5-Aza-2'-deoxycytidine; Filled circles: Methylated CpG sites; IVD: In vitro methylated DNA; M: Methylated alleles; NL: Normal lymphocyte DNA; Open circles: Unmethylated CpG sites; RT: Reverse transcription;

TSS: transcription start site; U: Unmethylated alleles. 


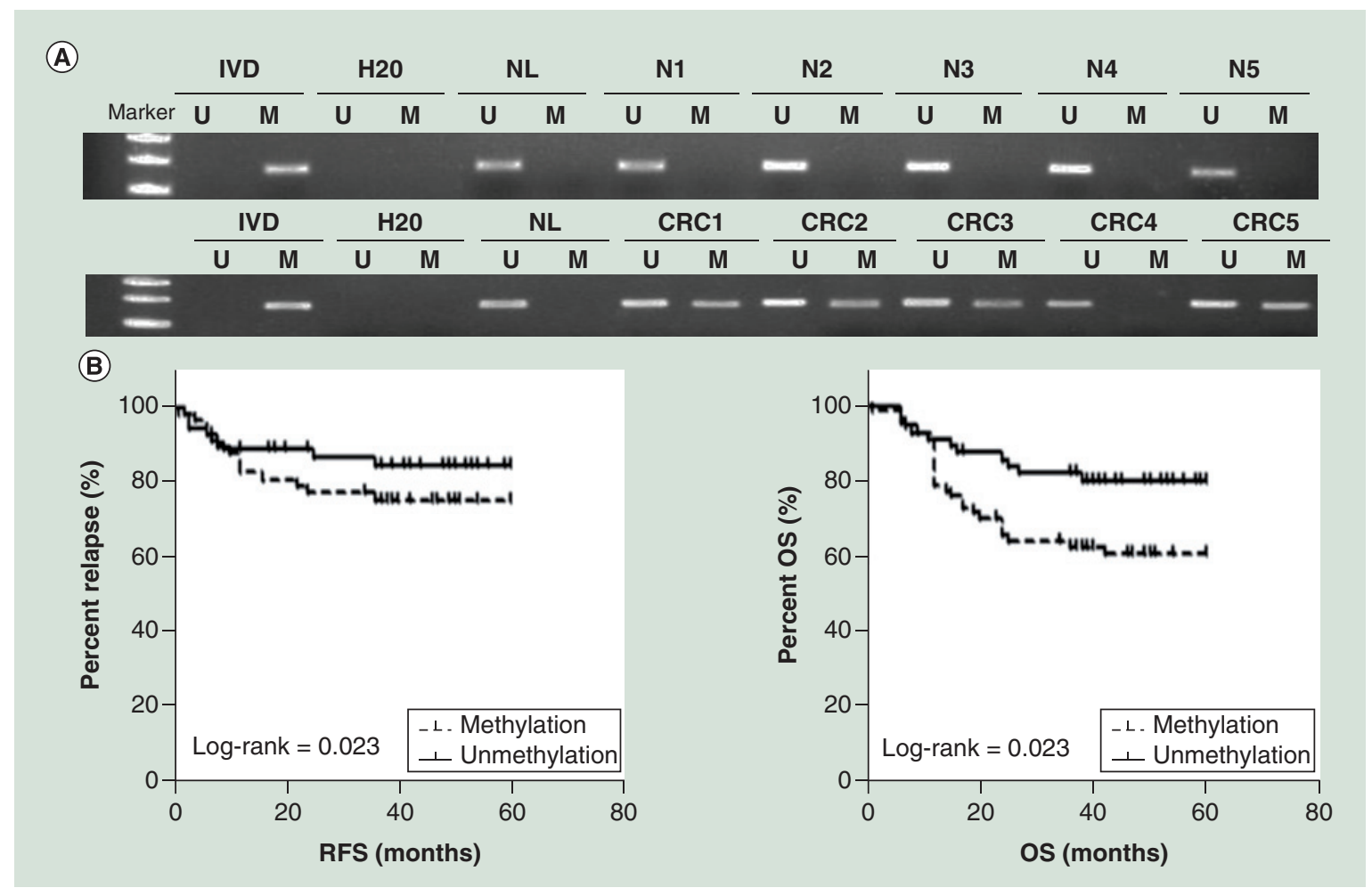

Figure 2. SLFN11 is frequently methylated in human primary colorectal cancer tissues and the role of SLFN11 in overall survival and relapse-free survival in colorectal cancer patients. (A) Representative MSP results of SLFN11 in normal colorectal tissues (N1, N2, N3, N4 and N5) and primary CRC tissues. (B) SLFN11 methylation status is associated with RFS and OS of CRC patients.

CRC: Colorectal cancer; OS: Overall survival; RFS: Relapse-free survival.

UUGCGAUAUATT-3'; antisense: 5'-UAUAUCGCAAAUAUCCUGGTT-3'); RNAi negative control duplex (sense: 5'-UUC UCC GAA CGU GUC ACG UTT-3'; and antisense: 5'-ACG UGA CAC GUU CGG AGA ATT-3'). RNAi oligonucleotide or RNAi negative control duplex was transfected into SLFN11 highly expressed DKO cells using Lipofectamine RNAiMAX (Invitrogen, CA, USA).

\section{Cell viability assay}

Cells were plated into 96-well plates at a density of $2 \times 10^{3}$ cells per well, and cell viability was measured by the methyl thiazolyl tetrazolium assay (KeyGEN Biotech, Nanjing, China) at 0, 24, 48 and 72 h. Absorbance was measured on a microplate reader of Thermo Multiskan MK3 (Termo Fisher Scientific, MA, USA) at a wavelength of $490 \mathrm{~nm}$.

The $\mathrm{IC}_{50}$ was also detected by the MTT assay. Cells were plated at a density of 3000 cells per well into 96-well plates. After overnight incubation, cells were treated with cisplatin at concentrations of $0,1,2.5,5$, 10,25 and $50 \mu \mathrm{M}$ for $48 \mathrm{~h}$.

\section{Colony formation assay}

SLFN11 stably expressed and unexpressed RKO and
DLD1 cells were plated onto 6-well plates in a total of 200 cells per well. After 2 weeks, cells were fixed with $75 \%$ ethanol for $30 \mathrm{~min}$. Colonies were then stained with $0.5 \%$ crystal violet solution and counted. The experiment was performed in triplicate. Another method was employed in this study to further validate the results. The detailed protocol was described as previously [20]. In brief, SLFN11 stably expressed and unexpressed RKO and DLD1 cells were plated at a confluency of $6 \times 10^{4}$ cells per $6-\mathrm{cm}$ dish. Media were replenished every 2 days. After 7-10 days, cells were stained with crystal violet in formalin for $30 \mathrm{~min}$. After excess stain was washed away, colonies were imaged and the percent plate coverage is indicated as determined from five independent areas per plate using ImageJ software.

After $48 \mathrm{~h}$ of transfection, the SLFN11 expressing DKO cells and DKO cells with knockdown of SLFN11 were treated as mentioned above.

\section{Colony formation assay treated with cisplatin}

This was performed as previously reported [21]. For the colony-forming assay, SLFN11 stably expressed and unexpressed RKO and DLD1 cell lines were plated onto 6-well plates in a total of 1000 cells per well. 
After overnight incubation, cells were treated with cisplatin $(2 \mu \mathrm{M})$ for $24 \mathrm{~h}$ and maintained in a drug-free medium for an additional 2 weeks until visible colonies were evident. After staining with the $0.5 \%$ crystal violet, the number of colonies of $>0.1 \mathrm{~mm}$ in diameter was counted. After $48 \mathrm{~h}$ post transfection, DKO cells and DKO cells with knockdown of SLFN11 were treated as mentioned above.

Flow cytometry for cell cycle \& apoptosis SLFN11 stably expressed and unexpressed RKO and DLD1 cell lines were plated into 6-well plates at $1 \times 10^{6}$ cells per well. The cells were harvested at $48 \mathrm{~h}$, washed with phosphate-buffered saline twice and stained according to manufacturer's instructions of Cycletest ${ }^{\mathrm{TM}}$ Plus DNA Reagent Kit (Becton, Dickinson and company, CA, USA). Samples were analyzed with an FACS Caliber flow cytometer (Becton, Dickinson and company).

Apoptosis was detected and quantified by Annexin V-FITC and propidium iodide staining. SLFN11 stably expressed and unexpressed RKO and DLD1

\section{Table 2. Clinic-pathological features and SLFN11 methylation status in colorectal cancer patients.}

Clinical parameter Number $(n=128)$

Methylation status

p-value

Methylated $\mathrm{n}=\mathbf{7 1}$ Unmethylated $\mathrm{n}=\mathbf{5 7}$

(55.47\%)

$(44.53 \%)$

Age

\begin{tabular}{ll}
0.02 \\
\hline
\end{tabular}

$\begin{array}{llll}<50 & 30 & 11 & 19 \\ \geq 50 & 98 & 60 & 38\end{array}$

Gender

$\geq 50$

60

38

$\begin{array}{lllll}\text { Male } & 84 & 50 & 34 \\ & \text { Female } & 44 & 21 & 23\end{array}$

Tumor differentiation

Poor $\quad 35 \quad 19 \quad 16$

$\begin{array}{llll}\text { Moderate and well } & 93 & 52 & 41\end{array}$

Lymphatic metastasis

$\begin{array}{llll}\text { No } & 69 & 39 & 30 \\ \text { Yes } & 59 & 32 & 27\end{array}$

Size

Yes

\begin{tabular}{|c|c|c|c|c|c|}
\hline & $<5 \mathrm{~cm}$ & 66 & 33 & 33 & \\
\hline & $\geq 5 \mathrm{~cm}$ & 62 & 38 & 24 & \\
\hline \multirow[t]{3}{*}{ Anatomical position } & & & & & 0.58 \\
\hline & Proximal & 83 & 48 & 35 & \\
\hline & Distal & 45 & 23 & 22 & \\
\hline \multirow[t]{3}{*}{ T stage } & & & & & 1.00 \\
\hline & Stages I and II & 64 & 35 & 29 & \\
\hline & Stages III and IV & 64 & 36 & 28 & \\
\hline \multirow[t]{3}{*}{ KRAS mutation } & & & & & 0.136 \\
\hline & Wide-type & 99 & 51 & 48 & \\
\hline & Mutation & 29 & 20 & 9 & \\
\hline \multirow[t]{3}{*}{ CIMP } & & & & & 0.173 \\
\hline & CIMP(-) & 90 & 46 & 44 & \\
\hline & $\mathrm{CIMP}(+)$ & 38 & 25 & 13 & \\
\hline \multirow[t]{2}{*}{ BRAF 600E mutation } & Wide-type & 125 & 69 & 56 & 1.00 \\
\hline & Mutation & 3 & 2 & 1 & \\
\hline
\end{tabular}


Table 3. Univariate and multivariate analysis of SLFN11 methylation status with relapse-free survival or overall survival in colorectal cancer patients.

\begin{tabular}{|c|c|c|c|c|c|c|c|c|}
\hline \multirow[t]{3}{*}{ Clinical parameter } & \multicolumn{4}{|c|}{ RFS } & \multicolumn{4}{|c|}{ OS } \\
\hline & \multicolumn{2}{|c|}{ Univariate analysis } & \multicolumn{2}{|c|}{ Multivariate analysis } & \multicolumn{2}{|c|}{ Univariate analysis } & \multicolumn{2}{|c|}{ Multivariate analysis } \\
\hline & HR $(95 \% \mathrm{Cl})$ & p-value & HR $(95 \% \mathrm{Cl})$ & p-value & HR $(95 \% \mathrm{Cl})$ & p-value & HR $(95 \% \mathrm{Cl})$ & p-value \\
\hline Age ( $<50$ vs $\geq 50$ years) & $\begin{array}{l}1.391 \\
(0.613-3.16)\end{array}$ & 0.430 & & & $\begin{array}{l}1.395 \\
(0.614-3.168)\end{array}$ & 0.427 & & \\
\hline $\begin{array}{l}\text { Gender (male vs } \\
\text { female) }\end{array}$ & $\begin{array}{l}1.15 \\
(0.60-2.22)\end{array}$ & 0.681 & & & $\begin{array}{l}1.105 \\
(0.571-2.137)\end{array}$ & 0.767 & & \\
\hline $\begin{array}{l}\text { Tumor location } \\
\text { (proximal colon vs } \\
\text { distal colon or rectum) }\end{array}$ & $\begin{array}{l}0.631 \\
(0.307-1.3)\end{array}$ & 0.212 & & & $\begin{array}{l}0.634 \\
(0.308-1.306)\end{array}$ & 0.216 & & \\
\hline $\begin{array}{l}\text { Tumor size }(<5 \text { vs } \\
\geq 5 \mathrm{~cm})\end{array}$ & $\begin{array}{l}1.25 \\
(0.661-2.363)\end{array}$ & 0.492 & & & $\begin{array}{l}1.228 \\
(0.65-2.322)\end{array}$ & 0.527 & & \\
\hline $\begin{array}{l}\text { Differentiation (high } \\
\text { or middle vs low } \\
\text { differentiation) }\end{array}$ & $\begin{array}{l}0.465 \\
(0.244-0.886)\end{array}$ & 0.020 & $\begin{array}{l}0.225 \\
(0.335-1.293)\end{array}$ & 0.225 & $\begin{array}{l}0.465 \\
(0.244-0.885)\end{array}$ & 0.020 & $\begin{array}{l}0.672 \\
(0.341-1.325)\end{array}$ & 0.251 \\
\hline $\begin{array}{l}\text { Pathologic } T \text { stage } \\
\text { (T3-4 vs T1-2) }\end{array}$ & $\begin{array}{l}1.797 \\
(0.638-5.065)\end{array}$ & 0.268 & & & $\begin{array}{l}1.864 \\
(0.661-5.255)\end{array}$ & 0.239 & & \\
\hline $\begin{array}{l}\text { Pathologic N stage } \\
\text { (N1-2 vs N0) }\end{array}$ & $\begin{array}{l}3.369 \\
(1.668-6.805)\end{array}$ & 0.001 & $\begin{array}{l}3.061 \\
(1.465-6.394)\end{array}$ & 0.003 & $\begin{array}{l}3.367 \\
(1.668-6.795)\end{array}$ & 0.001 & $\begin{array}{l}3.053 \\
(1.456-6.401)\end{array}$ & 0.003 \\
\hline $\begin{array}{l}\text { SLFN11 absence of } \\
\text { methylation }\end{array}$ & $\begin{array}{l}0.461 \\
(0.229-0.93)\end{array}$ & 0.031 & $\begin{array}{l}0.442 \\
(0.219-0.891)\end{array}$ & 0.023 & $\begin{array}{l}0.457 \\
(0.227-0.923)\end{array}$ & 0.029 & $\begin{array}{l}0.439 \\
(0.217-0.887)\end{array}$ & 0.022 \\
\hline $\begin{array}{l}\text { KRAS mutation (wide- } \\
\text { type and mutation) }\end{array}$ & $\begin{array}{l}1.804 \\
(0.909-3.580)\end{array}$ & 0.091 & & & $\begin{array}{l}1.799 \\
(0.906-3.572)\end{array}$ & 0.93 & & \\
\hline CIMP(-) and CIMP(+) & $\begin{array}{l}1.277 \\
(0.643-2.535)\end{array}$ & 0.485 & & & $\begin{array}{l}1.299 \\
(0.654-2.579)\end{array}$ & 0.455 & & \\
\hline
\end{tabular}

cell lines were seeded in 6-well plates at a density of $1.5 \times 10^{6}$ cells $/ \mathrm{ml}$. Cells were treated with a concentration of $10 \mu \mathrm{M}$ cisplatin for $36 \mathrm{~h}$. The cells were then harvested using $0.2 \%$ trypsin (no ethylenediaminetetraacetic acid), stained according to manufacturer's instructions of FITC Annexin V apoptosis Detection kit I (Becton, Dickinson and company), and analyzed by flow cytometry. After $48 \mathrm{~h}$ of transfection, DKO cells with and without knockdown of SLFN11 were treated with a concentration of $10 \mu \mathrm{M}$ cisplatin for $36 \mathrm{~h}$; apoptosis was detected.

\section{Protein preparation \& western blotting}

Cells were lysed in icecold Tris buffer $(20 \mathrm{mmol} / 1$ Tris; $\mathrm{pH} 7.5)$ containing $137 \mathrm{mmol} / \mathrm{l} \mathrm{NaCl}, 2 \mathrm{mmol} / \mathrm{l}$ ethylenediaminetetraacetic acid, $1 \%$ Triton $\mathrm{X}, 10 \%$ glycerol, $50 \mathrm{mmol} / \mathrm{l} \mathrm{NaF}, 1 \mathrm{mmol} / \mathrm{l}$ DTT and a protease inhibitor cocktail (Roche Applied Science, IN, USA). Protein concentrations were quantified using the BCA protein assay kit (CWBIO, Beijing, China). The protein lysates were then separated by SDS-PAGE and electroblotted onto polyvinylidene fluoride (PVDF) membranes (Hybond-P). After blocking with 5\% nonfat milk and $0.1 \%$ Tween-20 in tris buffered saline (TBS), the membranes were incubated with antibodies.

The antibodies for immunoblot analysis were as follows: SLFN11 (1:200, Santa Cruz Biotechnology, CA, USA), cyclin D1 (1:500, Proteintech, IL, USA), cyclin E1 (1:500, Proteintech, IL, USA) and $\beta$-actin (1:1000 Beyotime Biotech, Jiangsu, China). $\beta$-actin antibody was used as a loading control. The blots were visualized using enhanced chemiluminescence (Pierce Bioscience, IL, USA).

SLFN11 unexpressed \& re-expressed DLD1 cell xenograft mouse model

Animal experiments were reviewed and approved by the Chinese PLA General Hospital Experimental Animal Committee. SLFN11 unexpressed and SLFN11 stably expressed DLD1 cells were injected subcutaneously into the dorsal left side of 4-week-old male Balb/c nude mice $(\mathrm{n}=10$ ) weighing $12-18 \mathrm{~g}$. Tumor volumes were measured every 4 days for 20 days starting 4 days after implantation. Tumor volumes were calculated accord- 
ing to the formula: $\mathrm{V}=\mathrm{L} \times \mathrm{W}^{2} / 2$, where $\mathrm{V}$ represents the volume $\left(\mathrm{mm}^{3}\right)$, L represents largest length $(\mathrm{mm})$ and W represents width $(\mathrm{mm})$, respectively. Mice were sacrificed after 20 days.

\section{Statistical analysis}

Statistical analysis was performed using SPSS 17.0 software (SPSS, IL, USA). Either $\chi^{2}$ or Fisher's exact tests were used to evaluate the relationship between methylation status and clinicopathological characteristics. The two-tailed independent samples' t-test was applied to determine the statistical significance of the differences between the two experimental groups. Survival rates were calculated by the Kaplan-Meier method, and differences in survival curve were evaluated using the log-rank test. Cox proportional hazards models were fit to determine independent associations of SLFN11 methylation with OS and relapse-free survival (RFS) outcome. Two-sided tests were used to determine significance, and $\mathrm{p}<0.05$ was considered statistically significant.

\section{Results}

The expression of SLFN11 is regulated by promoter region methylation in CRC

The expression levels of SLFN11 were examined by semiquantitative reverse transcription PCR (RTPCR) to explore the regulation of SLFN11 in CRC. SLFN11 was expressed in Ls180 and DKO cells and unexpressed in RKO, DLD1, SW620 and LOVO cells (Figure 1A). Complete methylation was observed in RKO, DLD1, SW620 and LOVO cells; partial methylation was detected in Ls180; and unmethylation was found in DKO cells (Figure 1B). MSP results were
(A)
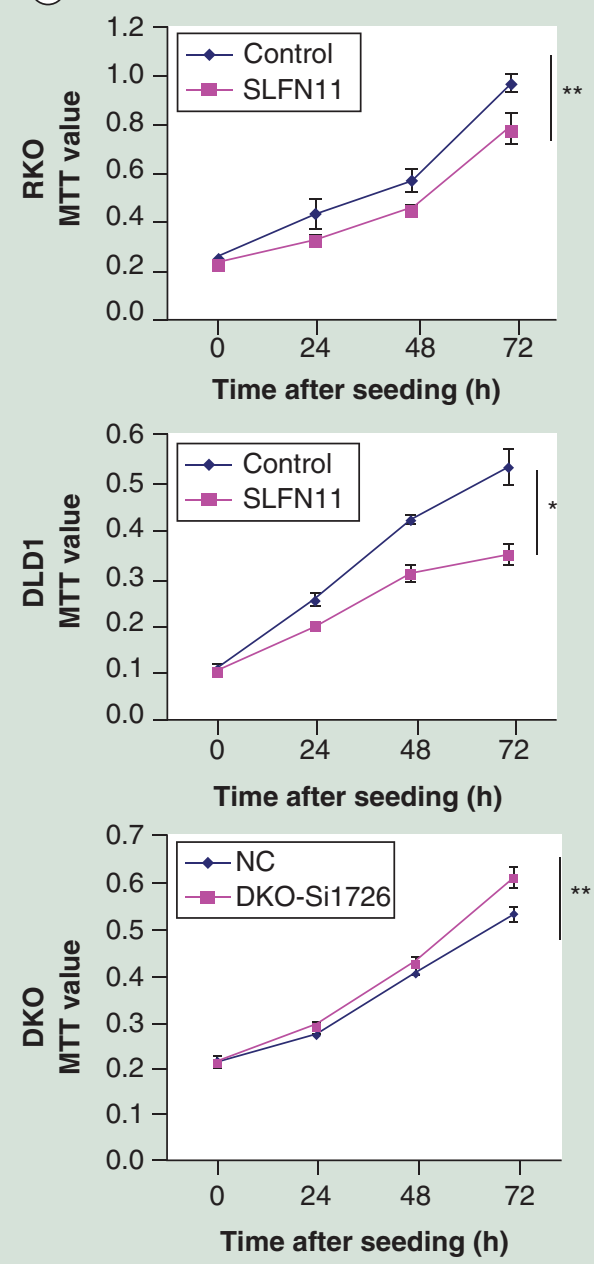

(B)
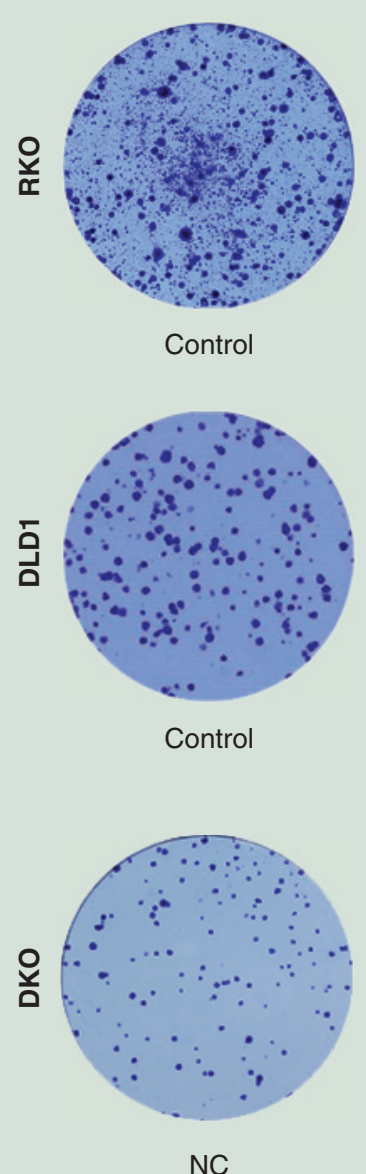

NC
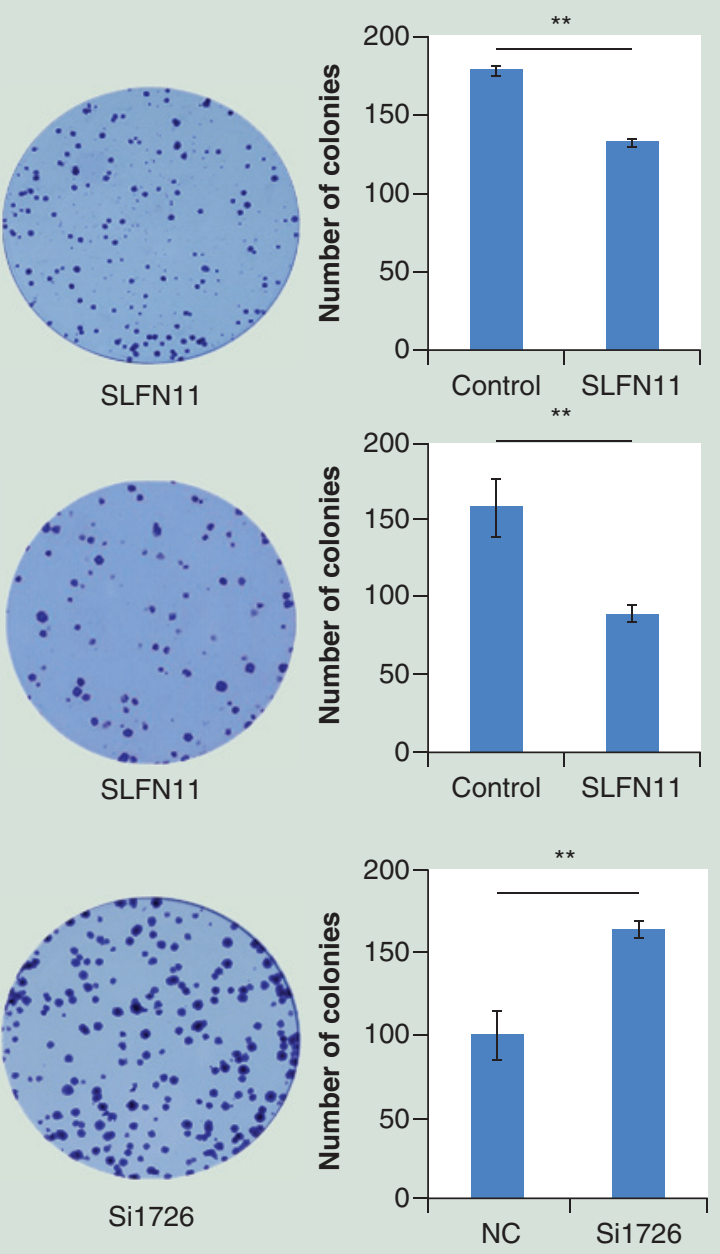

Figure 3. SLFN11 suppresses colorectal cancer cell proliferation. (A) The effect of SLFN11 on cell proliferation was measured by the MTT assay for $72 \mathrm{~h}-$ SLFN11: SFLN11 re-expressed CRC cells. Control: empty vector. ${ }^{*} \mathrm{p}<0.05,{ }^{* *} \mathrm{p}<0.01$. (B) The effects of SLFN11 on colony formation in colorectal cells; ${ }^{* *} \mathrm{p}<0.01$. 


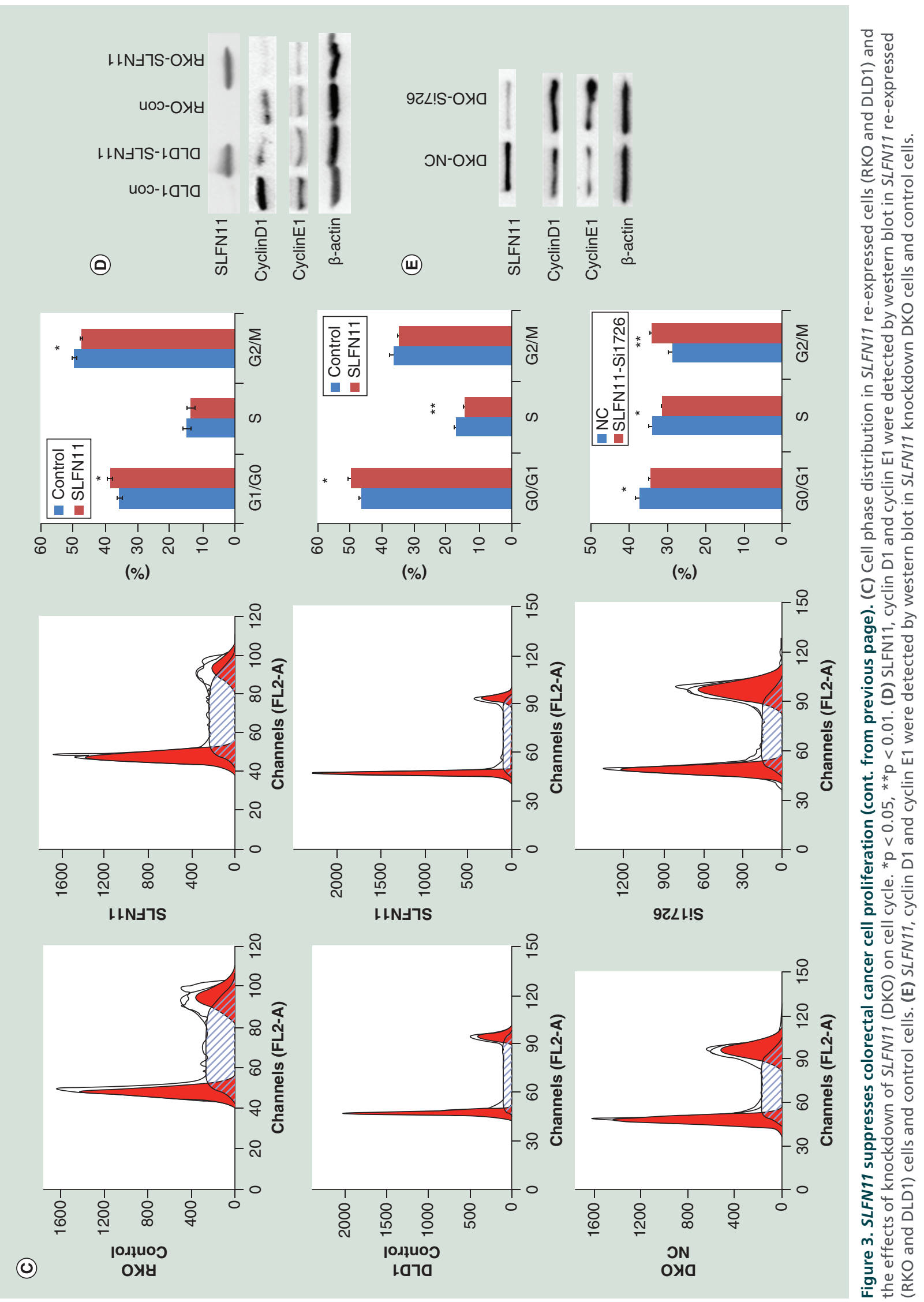


validated by BSSQ in RKO, DLD1 and Ls180 cells (Figure 1C). Loss of/reduced expression of SLFN11 was correlated with promoter region methylation. Upon treatment with 5-AZA, a demethylating agent, restoration of SLFN11 expression was observed in RKO, DLD1, SW620 and LOVO cells, and increased expression was detected in Ls180 (Figure 1A). No expression changes were detected in DKO cells. These results suggest that the expression of SLFN11 is regulated by promoter region methylation.

SLFN11 is frequently methylated in human CRC The methylation status of SLFN11 was detected by MSP (Figure 2A). SLFN11 was methylated in $55.47 \%$ (71/128) of CRC patient samples. No methylation was found in five cases of noncancerous colorectal mucosa. Methylation of SLFN11 was significantly associated with age, poor 5-year OS and 5-year RFS (all p < 0.05; Figure $2 \mathrm{~B} \&$ Table 2), while no association was found between SLFN11 methylation and gender, tumor differentiation, lymphatic metastasis, location, stage, size (all p > 0.05, Table 2). Among 128 cases of CRC, KRAS mutation was found in 29 cases $(22.66 \%)$, and $B R A F$ mutation in 3 cases $(2.34 \%)$. No association was found between SLFN11 methylation and KRAS or $B R A F$ mutation (all $\mathrm{p}>0.05$, Table 2). Among 128 cases of CRC, CIMP (+) was detected in 38 cases (29.69\%) and CIMP (-) in 90 cases (70.31\%). No association was found between SLFN11 methylation and CIMP $(+)$ in CRC ( $p>0.05$, Table 2).

Cox proportional hazards model analysis indicated that SLFN11 methylation was an independent prognostic factor for OS and RFS after adjusting for tumor differentiation and $\mathrm{N}$ stage (both $\mathrm{p}<0.05$, Table 3 ).

\section{SLFN11 suppresses CRC cell proliferation}

SLFN11 stably expressing cells were established by transfecting PCDH-SLFN11 expression vector into SLFN11 unexpressed RKO and DLD1 cells. MTT and colony formation assays were employed to evaluate the effects of SLFN11 on cell proliferation. The optical delnsity $(\mathrm{OD})$ values were $0.533 \pm 0.037$ versus $0.349 \pm 0.019(\mathrm{p}<0.05)$ in DLD1 cells and $0.968 \pm$ 0.037 versus $0.782 \pm 0.065(\mathrm{p}<0.01)$ in $\mathrm{RKO}$ cells before and after restoration of SLFN11 expression (Figure 3A). Re-expression of SLFN11 significantly suppressed colony formation in RKO and DLD1 cells (Figure 3B \& Supplementary Figure 1). The effects of SLFN11 on cell cycle were analyzed by flow cytometry. The cell phase distributions before and after re-expression of SLFN11 in DLD1 cells were as follows: G0/G1 phase: $45.93 \pm 2.05 \%$ versus $50.23 \pm 0.95 \%$, $S$ phase $17.51 \pm 0.24 \%$ versus $14.72 \pm 0.59 \%$ and $G 2 / M$ phase: $36.55 \pm 1.84 \%$ versus $35.05 \pm 0.57 \%$. In RKO cells, the cell phase distributions before and after re-expression of SLFN11 were as follows: G0/G1 phase: $35.57 \pm 0.82 \%$ versus $38.66 \pm 0.85 \%, S$ phase $14.77 \pm 0.98 \%$ versus $13.62 \pm 1.12$; and $\mathrm{G} 2 / \mathrm{M}$ phase: $49.66 \pm 0.75 \%$ versus $47.72 \pm 0.29 \%$. The number of cells in G1/G0 phase increased significantly after re-expression of SLFN11 in DLD1 and RKO cells (both $\mathrm{p}<0.05$, Figure 3C). To further validate these results, siRNA knockdown technique was employed. The OD values were $0.591 \pm$ 0.015 versus $0.677 \pm 0.022$ before and after knockdown of SLFN11 in DKO cells ( $<<0.05$, Figure 3A). Knockdown of SLFN11 significantly promotes colony formation in DKO cells (Figure 3B \& Supplementary Figure 1). The cell phase distributions before and after knockdown of SLFN11 were as follows: G0/G1 phase 37.36 $\pm 0.98 \%$ versus $34.36 \pm 0.43 \%, S$ phase $33.9 \pm 0.61 \%$ versus $31.41 \pm 0.05 \%$, and $\mathrm{G} 2 / \mathrm{M}$ phase $28.74 \pm 0.91 \%$ versus $34.23 \pm 0.44 \%$. The number of cells in G0/G1 phase was significantly reduced after knockdown of SLFN11 in DKO cells ( $\mathrm{p}<0.05$, Figure 3C).

To further validate the effects of SLFN11 on cell cycle, the levels of cyclin D1 and cyclin E1 were examined by western blot in DLD1 and RKO cells before and after re-expression of SLFN11. The expression levels of cyclin D1 and cyclin E1 were reduced after reexpression of SLFN11 in RKO and DLD1 (Figure 3D), while the expression levels of cyclin D1 and cyclin E1 were increased after knockdown of SLFN11 in DKO (Figure 3E). These results further suggest that SLFN11 inhibits cell proliferation in CRC.

\section{SLFN11 sensitized CRC cells to cisplatin}

The expression of SLFN11 has been reported to sensitize ovarian cancer to cisplatin-containing regimens [13]. To explore the sensitizing effects of SLFN11 on CRC cells, the MTT assay was employed. The $\mathrm{IC}_{50}$ values of cisplatin were $21.77 \pm 0.46$ versus $9.99 \pm 1.12 \mu \mathrm{M}$, $6.23 \pm 0.77$ versus $2.59 \pm 0.28 \mu \mathrm{M}$ and $17.56 \pm 0.30$ versus $13.19 \pm 1.48 \mu \mathrm{M}$ before and after re-expression of SLFN11 in RKO, DLD1 and SW620 cells, respectively. The $\mathrm{IC}_{50}$ values were significantly reduced after re-expression of SLFN11 (all $\mathrm{p}<0.05$, Figure 4A). The $\mathrm{IC}_{50}$ values were $14.19 \pm 0.21$ versus $24.20 \pm 2.51 \mu \mathrm{M}$ in DKO cell before and after knockdown of SLFN11. The $\mathrm{IC}_{50}$ value was significantly increased after knockdown of SLFN11 (all p $<0.05$, Figure 4A). These results suggest that SLFN11 sensitizes CRC cells to cisplatin.

Under treatment with $2 \mu \mathrm{M}$ of cisplatin, the number of colonies was $111 \pm 20$ versus $26.33 \pm 8.14$, $137.67 \pm 8.02$ versus $9.33 \pm 3.51$ and $47.50 \pm 10.61$ versus $10.00 \pm 4.00$ in RKO, DLD1 and SW620 cells, respectively, before and after re-expression of SLFN11. The colony numbers were reduced significantly after re-expression of SLFN11 in RKO, DLD1 and SW620 
(A)

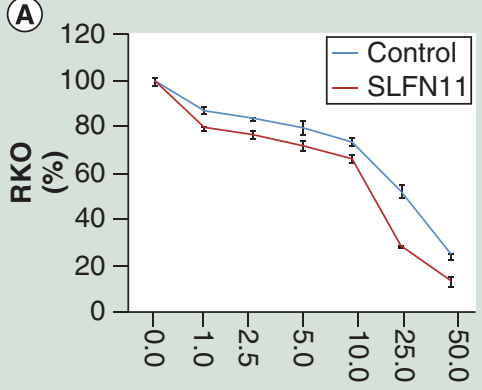

$\mu \mathrm{M}$

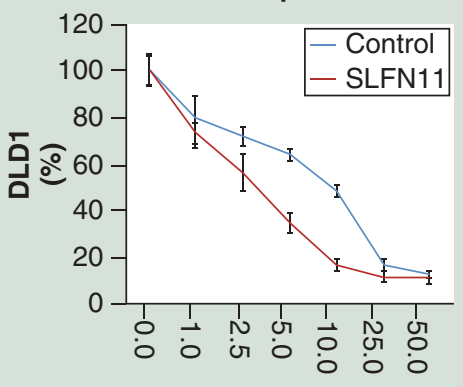

$\mu \mathrm{M}$

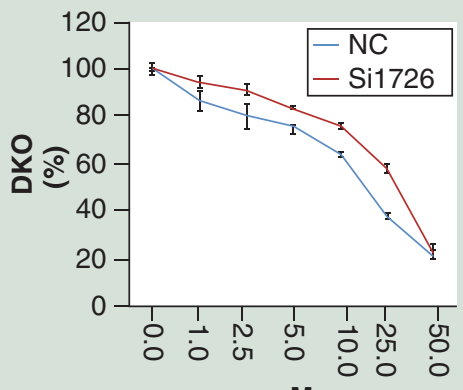

$\mu \mathrm{M}$

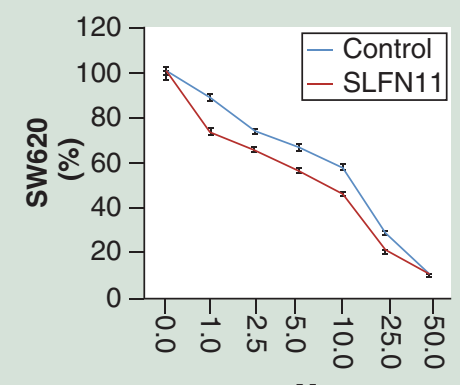

$\mu \mathrm{M}$
(B)
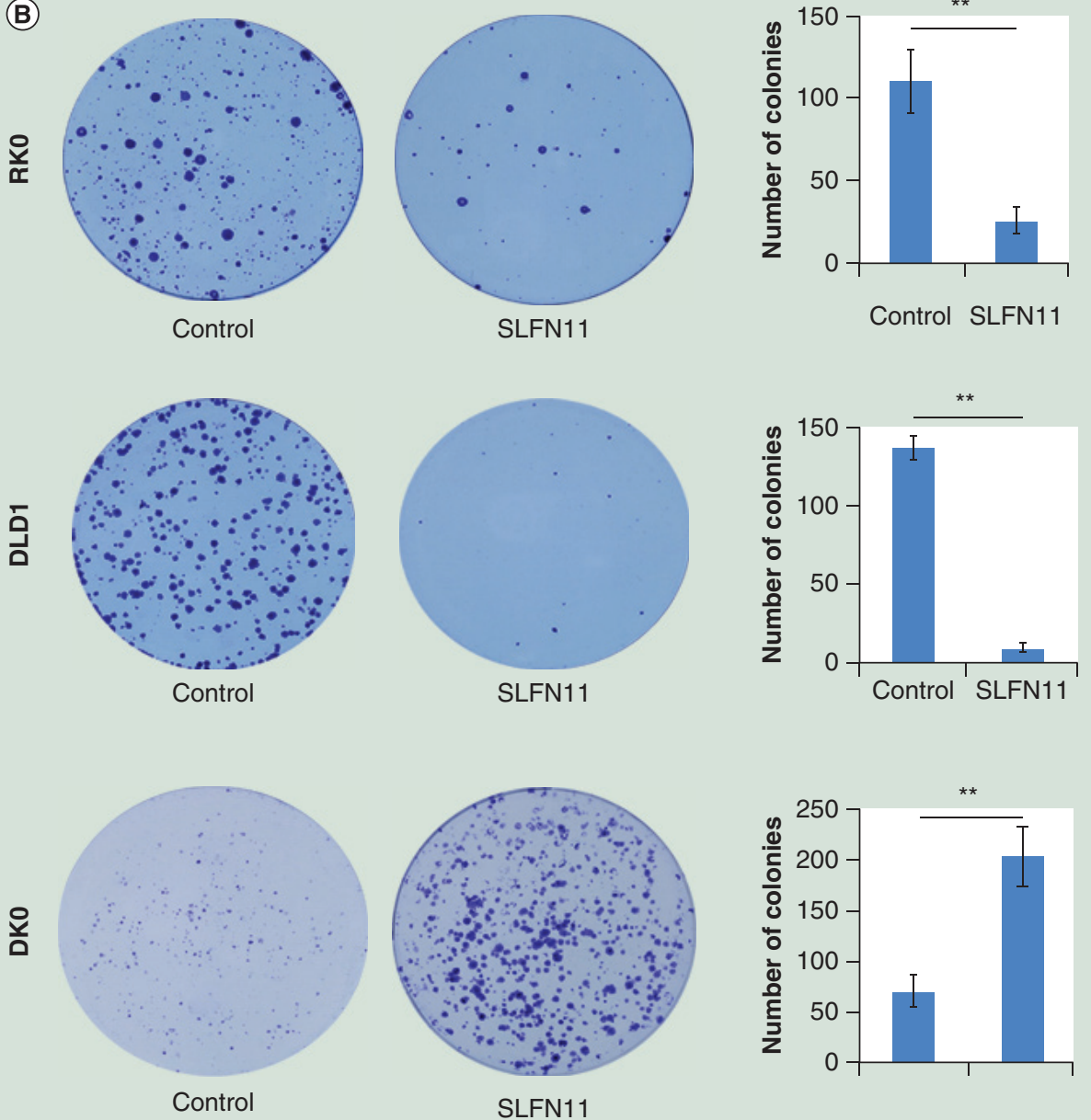

SLFN11
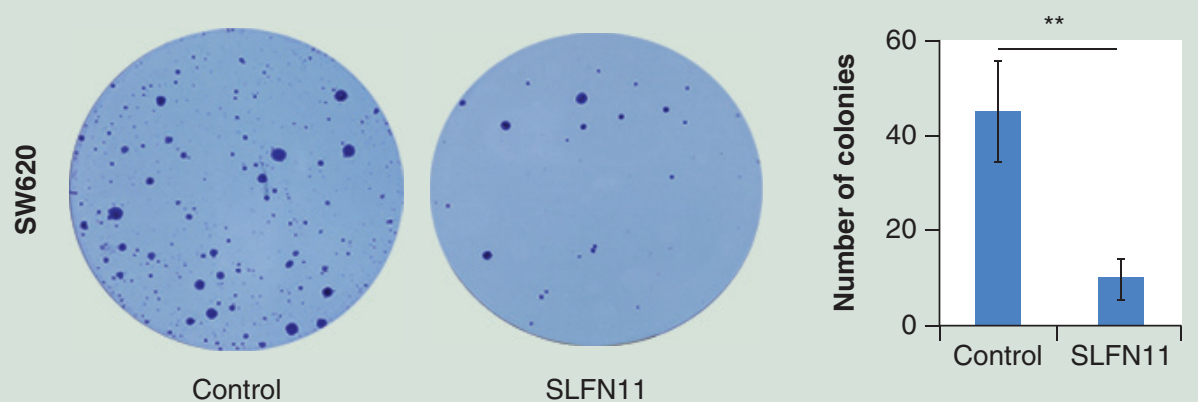

Figure 4. SLFN11 promotes chemosensitivity of colorectal cancer cells to cisplatin in vitro. (A) Cell viability determined by MTT assays following exposure to cisplatin. (B) Colony formation under treatment with $2 \mu \mathrm{M}$ of cisplatin in RKO, DLD1 and SW620 cells before and after re-expression of SLFN11, and in DKO cells before and after knockdown of SLFN11.

cells (all $\mathrm{p}<0.01$, Figure 4B). Upon treatment with $2 \mu \mathrm{M}$ of cisplatin, the number of colonies was 71.33 \pm 15.95 versus $204.66 \pm 28.15$ in DKO cells before and after knockdown of SLFN11. The colony numbers were increased significantly after knockdown of SLFN11 in DKO cells $(\mathrm{p}<0.01$, Figure $4 \mathrm{~B})$. These results further demonstrate that SLFN11 sensitizes CRC cells to cisplatin.
To further validate these results, the effects of SLFN11 on apoptosis were analyzed upon cisplatin treatment. Before and after re-expression of SLFN11 in RKO and DLD1 cells upon treatment with $10 \mu \mathrm{M}$ of cisplatin, the percentages of early apoptosis in lower right quadrant (LR) cells were $7.26 \pm 2.2 \%$ versus $16.82 \pm 1.81 \%(\mathrm{p}<$ $0.01)$ and $6.85 \pm 0.87 \%$ versus $9.68 \pm 0.64 \%$; the percentages of necrosis/late apoptosis in upper left quad- 
rant (UL) and upper right quadrant (UR) cells were $3.97 \pm 0.96 \%$ versus $10.15 \pm 1.61 \%$ and $3.89 \pm 0.05 \%$ versus $5.17 \pm 0.63 \%$, respectively ( $<<0.05$ ) (Figure $4 \mathrm{C}$ ). In DKO cells before and knockdown of SLFN11, the percentages of early apoptotic cells (LR) were $15.22 \pm$ $2.36 \%$ versus $9.37 \pm 0.49 \%(\mathrm{p}<0.05)$, and necrosis/late apoptosis (UL + UR) cells were $18.76 \pm 1.25 \%$ versus $15.09 \pm 0.69 \%(p>0.05)$, respectively (Figure 4C).

These results demonstrate that the amount of apoptosis induced by cisplatin treatment significantly increased after re-expression of SLFN11 and significantly decreased after knockdown of SLFN11. These results further suggest that SLFN11 sensitizes CRC cells to cisplatin.

\section{SLFN11 suppresses human CRC cell xenograft} growth in mice

To further investigate the effects of SLFN11 on CRC, SLFN11 unexpressed and re-expressed DLD1 cell xenograft mouse models were employed (Figure 5A). The tumor volumes were $372.83 \pm 79.59$ versus 133.11 $\pm 46.41 \mathrm{~mm}^{3}$ in SLFN11 unexpressed and re-expressed DLD1 cell xenografts $(p<0.01$; Figure $5 \mathrm{~B})$. The tumor weights were $0.15 \pm 0.04$ versus $0.07 \pm 0.02 \mathrm{~g}$
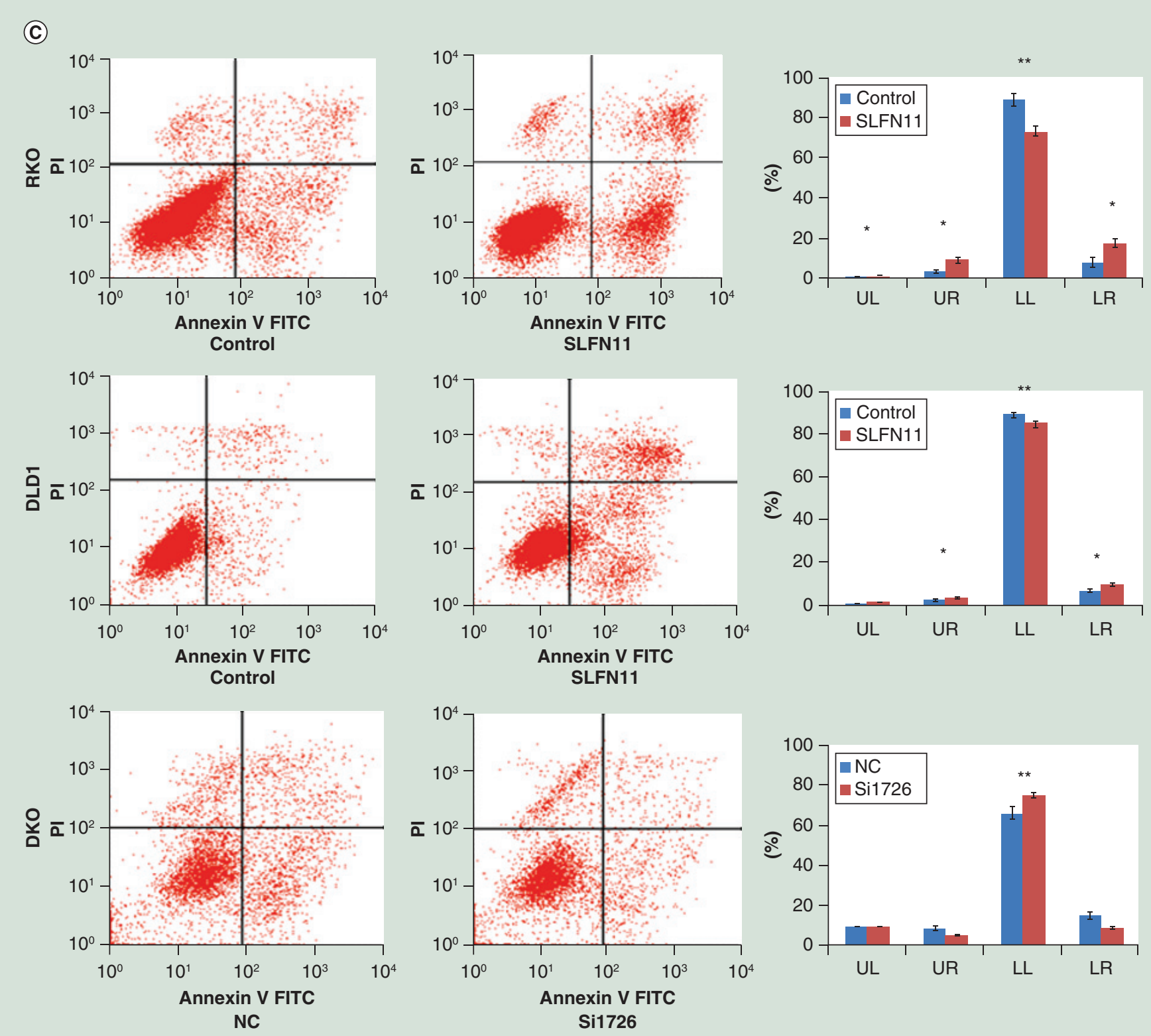

Figure 4. SLFN11 promotes chemosensitivity of colorectal cancer cells to cisplatin in vitro (cont. from facing page). (C) Apoptosis was detected and quantified by annexin V-FITC and propidium iodide staining. 


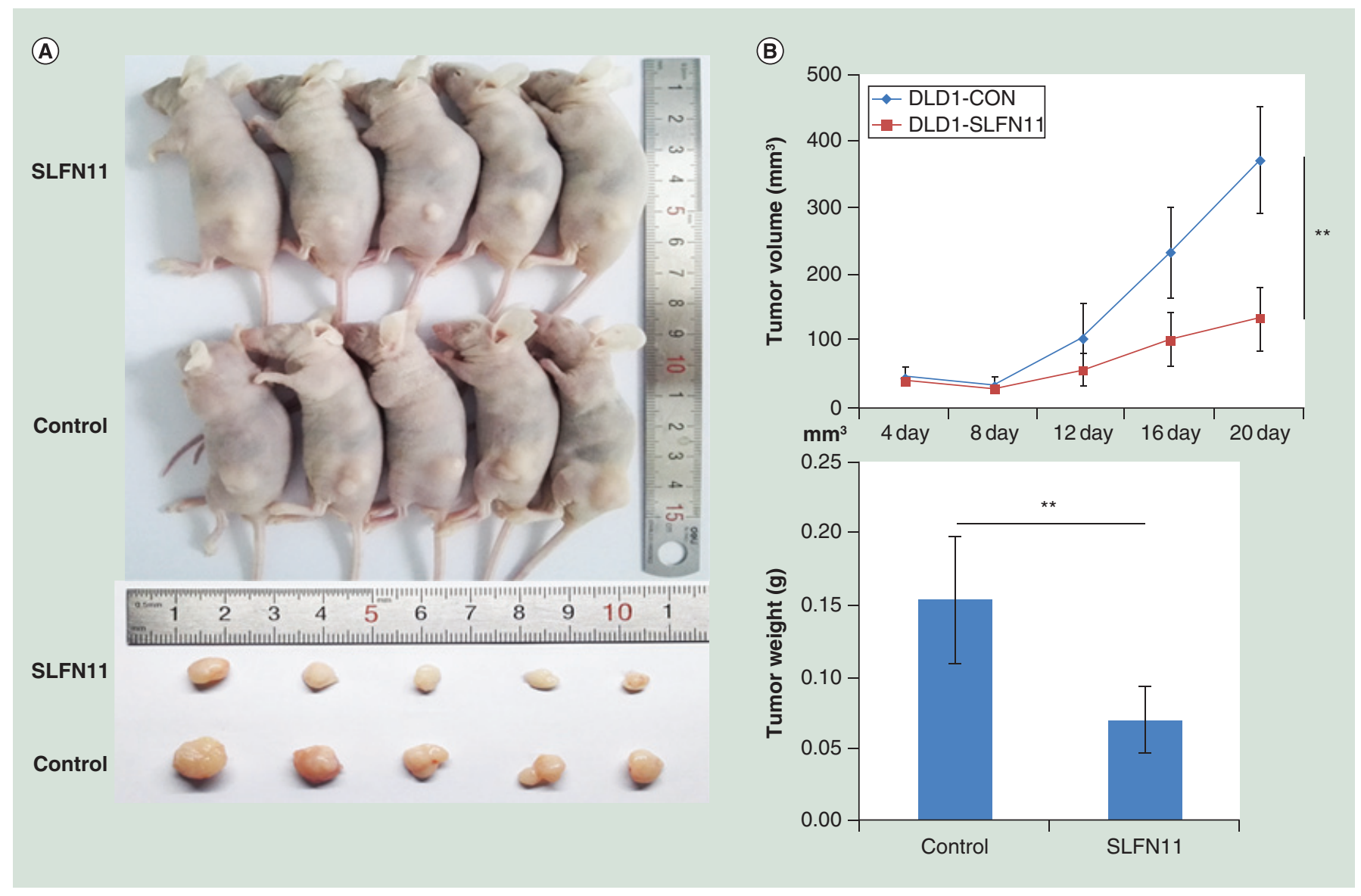

Figure 5. Inhibits tumor growth in colorectal cancer cell xenograft mice. (A) Results of SLFN11 re-expressed and unexpressed DLD1 cell xenografts in mice - top: SLFN11 re-expressed colorectal cells group; Bottom: control group. (B) Tumor growth curves and average weights of SLFN11 re-expressed and unexpressed DLD1 cell xenografts.

$* * p<0.01$.

in SLFN11 unexpressed and re-expressed DLD1 cell xenografts $(\mathrm{p}<0.01$; Figure $5 \mathrm{~B})$.

\section{Discussion}

In humans, there are only five SLFN members, SLFN12 is located in cytoplasm and the remaining members (SLFN5, SLFN11, SLFN13 and SLFN14) are localized to the nucleus [10]. The function of human $S L F N$ has not been extensively studied. Previous proteomic studies pointed to SLFN11 as a putative interactor of several key proteins of the DNA damage cell response system, such as replication proteins RPA1, RPA2 and RPA3 or BRCA1associated Ring Domain protein [14]. Nogales et al. found that SLFN11 methylation is a predictive biomarker of platinum resistance in ovarian and non-small-cell lung cancer by analyzing the DNA methylome database [14]. In another study, the authors found that SLFN11 sensitizes CRC cells to irinotecan [22]. Our study demonstrated that SLFN11 is methylated in $55.47 \%$ of human CRC samples, and the expression of SLFN11 is regulated by promoter region methylation. The results suggest that methylation of SLFN11 is involved in human CRC development and is a potential CRC detection marker. SLFN11 suppressed CRC growth both in vitro and in vivo. Methylation of SLFN11 may serve as a potential therapeutic target in CRC. Methylation of SLFN11 was significantly associated with age, poor 5-year OS and 5-year RFS, suggesting that SLFN11 methylation is a poor prognostic marker in CRC.

Defects of the DNA damage repair system can contribute to tumorigenesis and progression [23]. On the other hand, defects of DNA damage repair pathways may sensitize cancer cells to chemotherapy [24,25]. Human SLFN11 interacts with RPA and negatively regulates the DNA damage response by inhibiting checkpoint maintenance and homologous recombination repair [26]. Our study demonstrated that SLFN11 suppresses CRC cell proliferation by inducing G1/S arrest. In addition, SLFN11 sensitizes CRC cells to cisplatin. Thus, SLFN11 methylation may serve as a cisplatin insensitive marker. However, the chemotherapeutic regimens and other therapies were different in this population, it limited further analysis the association between SLFN11 methylation and each chemical agent. Because there is no reliable 
antibody available for SLFN11, we were not able to perform immunohistochemistry staining in primary CRC.

In conclusion, SLFN11 is frequently methylated in human CRC, and the expression of SLFN11 is regulated by promoter region methylation. Methylation of SLFN11 is associated with age, poor 5-year OS and 5-year RFS. SLFN11 suppresses CRC growth both in vitro and in vivo and SLFN11 sensitizes CRC cells to cisplatin.

\section{Future perspective}

SLFN11 is a candidate tumor suppressor in CRC. Methylation of SLFN11 may be a frequent event in $\mathrm{CRC}$ and is a potential detection and prognostic marker in CRC. Methylation of SLFN11 may serve as a cisplatin-resistant marker in CRC.

\section{Financial \& competing interests disclosure}

This work was supported by the following grants: National Basic Research Program of China (973 Program No.
2012CB934002); National Key research and development Programme (Programme No. 2016YFC1303600); National Key Scientific Instrument Special Programme of China (Grant No. 2011YQ03013405); National Science Foundation of China (NSFC Nos. 81672318 81402345, U1604281, 8167100001, 81230047 and 81490753); Beijing Science Foundation of China (BJSFC No. 7171008). JG Herman is a consultant to MDxHealth. The authors have no other relevant affiliations or financial involvement with any organization or entity with a financial interest in or financial conflict with the subject matter or materials discussed in the manuscript apart from those disclosed.

No writing assistance was utilized in the production of this manuscript.

\section{Open access}

This work is licensed under the Creative Commons Attribution 4.0 License. To view a copy of this license, visit http://creativecommons.org/licenses/by/4.0/

\section{Summary points}

- SLFN11 is frequently methylated in human colorectal cancer (CRC).

- The expression of SLFN11 is regulated by promoter region methylation.

- Methylation of SLFN11 is associated with age, poor 5-year overall survival and 5-year relapse-free survival.

- SLFN11 suppresses CRC growth both in vitro and in vivo.

- Methylation of SLFN11 reduced the sensitivity of CRC cells to cisplatin.

\section{References}

Papers of special note have been highlighted as:

- of interest; $\bullet \bullet$ of considerable interest

1 Ferlay J, Soerjomataram I, Dikshit R et al. Cancer incidence and mortality worldwide: sources, methods and major patterns in GLOBOCAN 2012. Int. J. Cancer 136(5), E359-E386 (2015).

2 Center MM, Jemal A, Smith RA, Ward E. Worldwide variations in colorectal cancer. CA Cancer J. Clin. 59(6), 366-378 (2009).

3 Armaghany T, Wilson JD. Chu Q, et al. Geneticalterations in colorectal cancer. Gastrointestinal cancer research. 5(1), 19-27( 2012).

4 Grady WM, Carethers JM. Genomic and epigenetic instability in colorectal cancer pathogenesis. Gastroenterology 135(4), 1079-1099 (2008).

-• Determining the causes and roles of genomic and epigenomic instability in colon tumor formation that has the potential toyield more effective prevention strategies and therapeutics for patients with colorectal cancer (CRC).

5 Nyberg KA, Michelson RJ, CW P, Weinert TA. Toward maintaining the genome: DNA damage and replication checkpoints. Annu. Rev. Genet. 36(1), 617 (2002).

6 Jasperson KW, Tuohy TM, Neklason DW, Burt RW. Hereditary and familial colon cancer. Gastroenterology 138(6), 2044-2058 (2010).
- Less than $5 \%$ of all CRC are caused bygene mutations in the DNA mismatch repair system, including familial adenomatous polyposis and Lynch syndrome.

7 Gao D, Herman JG, Guo M. The clinical value of aberrant epigenetic changes of DNA damage repair genes in human cancer. Oncotarget 7(24), 37331-37346 (2016).

- Aberrant methylation of DNA damagerepair gene is an important mechanism of CRC development.

8 Schwarz DA, Katayama CD, Hedrick SM. Schlafen, a new family of growth regulatory genes that affect thymocyte development. Immunity 9(5), 657-668 (1998).

9 Bustos O, Naik S, Ayers G et al. Evolution of the Schlafen genes, a gene family associated with embryonic lethality, meiotic drive, immune processes and orthopoxvirus virulence. Gene 447(1), 1-11 (2009).

10 Mavrommatis E, Fish EN, Platanias LC. The Schlafen family of proteins and their regulation by interferons. J. Interferon Cytokine Res. 33(4), 206-210 (2013).

11 De La Casa-Esperon E. From mammals to viruses: the Schlafen genes in developmental, proliferative and immune processes. Biomol. Concepts 2(3), 159-169 (2011).

- SLFN gene products are involved in cell biological processes, including proliferation, differentiation and immunefunction.

12 The Cancer Genome ATLAS. http://cancergenome.nih.gov

13 Zoppoli G, Regairaz M, Leo E et al. Putative DNA/RNA helicase Schlafen-11 (SLFN11) sensitizes cancer cells to 
DNA-damaging agents. Proc. Natl Acad. Sci. USA 109(37), 15030-15035 (2012).

- The expression of human SLFN11 was reported to sensitize cancer cells to DNA damaging agents.

14 Nogales V, Reinhold WC, Varma S et al. Epigenetic inactivation of the putative DNA/RNA helicase SLFN11 in human cancer confers resistance to platinum drugs. Oncotarget 7(3), 3084-3097 (2016).

15 Flejou JF. [WHO Classification of digestive tumors: the fourth edition]. Ann. Pathol. 31(Suppl. 5), S27-S31 (2011).

16 Morandi L. WO2011104695 A2 (2011).

17 Samowitz WS, Sweeney C, Herrick J et al. Poor survival associated with the BRAF V600E mutation in microsatellitestable colon cancers. Cancer Res. 65(14), 6063 (2005).

18 Herman JG, Graff JR, Myöhänen S, Nelkin BD, Baylin SB. Methylation-specific PCR: a novel PCR assay for methylation status of CpG islands. Proc. Natl Acad. Sci. USA 93(18), 9821-9826 (1996).

19 Ogino S, Kawasaki T, Kirkner GJ, Kraft P, Loda M, Fuchs CS. Evaluation of markers for CpG island methylator phenotype (CIMP) in colorectal cancer by a large populationbased sample. J. Mol. Diagn. 9(3), 305-314 (2007).

20 Basile KJ, Abel EV, Dadpey N, Hartsough EJ, Fortina P, Aplin AE. In vivo MAPK reporting reveals the heterogeneity in tumoral selection of resistance to RAF inhibitors. Cancer Res. 73(23), 7101-7110 (2013).

21 Zhang X, Yue P, Fletcher S, Zhao W, Gunning PT, Turkson J. A novel small-molecule disrupts Stat3 SH2 domainphosphotyrosine interactions and Stat3-dependent tumor processes. Biochem. Pharmacol. 79 (10), 1398 (2010).
22 Tian L, Song S, Liu X et al. Schlafen-11 platinum drugssensitizes colorectal carcinoma cells toirinotecan Anticancer Drugs 25(10), 1175-1181 (2014).

23 Bartkova J, Horejsí Z, Koed K et al. DNA irinotecan damage response as a candidate anti-cancer barrier in early human tumorigenesis. Nature 434(7035), 864-870 (2005).

- Defects of the DNA damage repair system can contribute totumorigenesis and progression.

24 Rottenberg S, Jaspers JE, Kersbergen A et al. High sensitivity tumorigenesis of BRCA1-deficient mammary tumors to the PARP inhibitor AZD2281 alone and in combination with platinum drugs. Proc. Natl Acad. Sci. USA 105(44), 17079-17084 (2008).

-. Defects of DNA damage repair pathways may sensitizecancer cells to chemotherapy.

25 Zaanan A, Cuilliere-Dartigues P, Guilloux A et al. Impact of $\mathrm{p} 53$ expression and microsatellite instability on stage III colon cancerdisease-free survival in patients treated by 5 -fluorouracil and leucovorin withor without oxaliplatin. Annals of oncology: official journal of the European Society for Medical Oncology / ESMO 21(4), 772-780 (2010).

$26 \mathrm{Mu}$ Y, Lou J, Srivastava M et al. SLFN11 inhibits checkpoint maintenance and homologous recombination repair. $E M B O$ Rep. 17(1), 94-109 (2016).

-• Human SLFN11 interacts with RPA and negatively regulates the DNA damage response by inhibiting checkpoint maintenance and homologous recombination repair. 